\title{
Diagnostic inertia in dyslipidaemia: results of a preventative programme in Spain.
}

Antonio Palazón-Bru, Armina Sepehri, Dolores Ramírez-Prado, Felipe Navarro-Cremades, Ernesto Cortés, María M Rizo-Baeza, Vicente F Gil-Guillén

Others have analysed the relationship between inadequate behaviour by healthcare professionals in the diagnosis of dyslipidaemia (diagnostic inertia) and the history of cardiovascular risk factors. However, since no study has assessed cardiovascular risk scores as associated factors we carried out a study to quantify diagnostic inertia in dyslipidaemia and determine if cardiovascular risk scores are associated with this inertia. In the Valencian Community (Spain) a preventive programme (cardiovascular, gynaecologic and vaccination) was started in 2003 inviting persons aged $\geq 40$ years to undergo a health check-up at their health centre. This cross-sectional study examined persons with no known dyslipidaemia seen during the first six months of the programme $(\mathrm{n}=16,905)$ but whose total cholesterol (TC) was $\geq 5.17 \mathrm{mmol} / \mathrm{L}$. Diagnostic inertia was defined as lack of follow-up to confirm/discard the dyslipidaemia diagnosis. Other variables included in the analysis were gender, history of cardiovascular risk factors/cardiovascular disease, counselling (diet/exercise), body mass index (BMI), age, blood pressure, fasting blood glucose and lipids. TC was grouped as $\geq /<6.20 \mathrm{mmol} / \mathrm{L}$. In patients without cardiovascular disease and $<75 / \leq 65$ years $(n=15,778 / 13,597)$ the REGICOR (REgistre GIroní del COr)/SCORE (Systematic COronary Risk Evaluation) cardiovascular risk functions were used to classify risk (high/low). Inertia was quantified and the adjusted odds ratios calculated from multivariate models. In the overall sample the rate of diagnostic inertia was 52\% (95\% Cl: 51.2-52.7\%); associated factors were TC $\geq 6.20 \mathrm{mmol} / \mathrm{L}$, high or "not measured" BMI, hypertension, smoking and higher values of fasting blood glucose, systolic blood pressure and TC. In the REGICOR sample the rate of diagnostic inertia was $51.9 \%$ (95\% Cl: 51.1-52.7\%); associated factors were REGICOR high and high or "not measured" BMI. In the SCORE sample the rate of diagnostic inertia was $51.7 \%$ (95\% Cl: 50.9-52.5\%); associated factors were SCORE high and high or "not measured" BMI. Diagnostic inertia existed in over half the patients and was associated with a greater cardiovascular risk. 
1 Authors: Antonio Palazón-Bru ${ }^{1}$, Armina Sepehri ${ }^{1}$, Dolores Ramírez-Prado ${ }^{1}$, Felipe Navarro-

2 Cremades ${ }^{1}$, Ernesto Cortés ${ }^{2}$, Mercedes Rizo-Baeza ${ }^{3}$, Vicente Francisco Gil-Guillén ${ }^{1}$.

3 Institutions:

4 1. Department of Clinical Medicine, Miguel Hernández University, San Juan de Alicante, Spain.

5 2. Department of Pharmacology, Paediatrics and Organic Chemistry, Miguel Hernández

6 University, San Juan de Alicante, Spain.

7 3. Department of Nursing, University of Alicante, San Vicente del Raspeig, Spain.

8 Corresponding author: Prof. Antonio Palazón-Bru, PhD Departament of Clinical Medicine,

9 Miguel Hernández University, Carretera de Valencia-Alicante S/N, San Juan de Alicante 03550,

10 Spain. Phone: +34 965919449. Fax: +34 965919450. E-mail: antonio.pb23@gmail.com 


\section{INTRODUCTION}

Despite the great advances in medicine, coronary heart disease (CHD) and stroke have remained the main causes of death worldwide for over a decade (WHO, 2014). Mathematical models based on scoring systems have been used to determine the main risk factors for these diseases. These factors can be classified as non-modifiable (male gender and older age) and modifiable (altered lipid levels, diabetes mellitus, high blood pressure and smoking). These latter factors should be acted on via early detection and control, with the aim of reducing the incidence of cardiovascular diseases (Wilson et al., 1998; Conroy et al., 2003; Marrugat et al., 2007; WHO, 2007).

The detection of dyslipidaemia (altered lipid levels in blood) requires obtaining the blood concentration of lipids (mean of two fasting measurements) and determining whether that concentration is altered (NCEP and ATP III, 2002). In Spain, in 2003, the total cholesterol (TC) concentration was used to diagnose dyslipidaemia (Villar Alvarez et al., 2003), with altered values being defined as TC $\geq 5.17 \mathrm{mmol} / \mathrm{L}$ (NCEP and ATP III, 2002; Villar Alvarez et al., 2003). This meant that if a patient had a TC concentration above this threshold, that patient should undergo a second measurement to confirm or discard the diagnosis of dyslipidaemia (NCEP and ATP III, 2002; Villar Alvarez et al., 2003). If, after this second measurement, the physician then diagnoses dyslipidaemia, he or she should act according to the relevant guidelines. This action involves various possibilities, including dietary and hygiene measures or pharmacologic treatment (statins, fibrates and resins) (NCEP and ATP III, 2002; Villar Alvarez et al., 2003).

In 2010 diagnostic inertia was defined as a derivation of clinical inertia, as defined by Phillips in 2001 (Phillips et al., 2001; Gil-Guillén et al., 2010). Diagnostic inertia was defined as a situation in which a patient fulfilled the diagnostic criteria for a particular disorder but was not 
diagnosed by the respective physician as having this disorder (Gil-Guillén et al., 2010). A paper published in 2014 examined this concept in dyslipidaemia, considering the concentrations of TC and high-density lipoprotein cholesterol (HDL-C). This paper also undertook an exhaustive literature search detailing the main characteristics of those studies that had assessed failures in the diagnosis of dyslipidaemia, even though these studies had not in fact used the term diagnostic inertia to refer to these failures (Palazón-Bru et al., 2014).

Some of these authors evaluated the history of cardiovascular risk factors (CVRF) in relation to diagnostic inertia (Palazón-Bru et al., 2014), but none of them assessed the cardiovascular risk using a scoring system obtained through a multivariate model, considering the current status of the patients (current situation regarding CVRF; for example, current TC or HDL-C levels), rather than the already diagnosed CVRF. Therefore, we conducted a study calculating the cardiovascular risk in the patients using the following scoring systems: REGICOR (REgistre GIroní del COr) (calibration for Spanish persons of one of the scales of the Framingham study to evaluate morbidity and mortality due to coronary disease) and SCORE (Systematic COronary Risk Evaluation) (cardiovascular risk function in Europe, version TC/ HDL-C) (Wilson et al., 1998; Conroy et al., 2003; Marrugat et al., 2007). We then examined the association of these cardiovascular risk scores in relation to the behaviour of the healthcare professionals. This type of association was examined by Sepehri et al. in their analysis of lack of advice to obese patients about losing weight (Sepehri et al., 2014). However, we have been unable to find any studies that analysed the situation as we proposed to do in this study. Accordingly, the results are innovative and highlight the need for measures to improve the diagnosis of dyslipidaemia. 
MATERIALS \& METHODS

\section{Setting}

The Valencian Community (Spain) had 4,518,126 inhabitants in 2004 (Instituto Nacional de Estadística, 2004). Primary healthcare is provided at health centres; coverage is universal and there is no cost to the patient. In this Community a preventive activities programme following the recommendations of the Spanish guidelines was started at the end of 2003, aimed at the whole population aged 40 years or over (Pareja Bezares et al., 1999; Villar Alvarez et al., 2003; Robledo de Dios et al., 2003; Del Cura González, Arribas Mir \& Coutado, 2003). Each person was invited, first by normal mail and then by telephone, to attend their health centre for a preventive study by medical and nursing personnel. The participants were given a report with the result of the examination and opportune recommendations, a copy of which was kept at the health centre. This programme included cardiovascular and gynaecologic screening and a vaccination campaign. The healthcare professionals who participated in this programme were dedicated solely to this job.

\section{Study population}

The study comprised all the patients who attended their health centres for the preventive activities programme. The main characteristics of these persons were: high prevalence of CVRF, older age, mostly women, and frequent attenders (Pedrera Carbonell et al., 2005).

\section{Study design and participants}

This was a cross-sectional study that analysed a sample of all individuals without known dyslipidaemia who were $\geq 40$ years and who participated during the first six months in the preventive activities programme of the Valencian Community but who had an altered screening for TC (TC $\geq 5.17 \mathrm{mmol} / \mathrm{L})$ (NCEP and ATP III, 2002; Villar Alvarez et al., 2003). 
Dyslipidaemia was defined according to the ICD-9-CM (272.x). Any patient who failed to fulfil these requirements was excluded from this study.

\section{Variables and measurements}

For this study we included all the cardiovascular data measured during the programme.

Diagnostic inertia was the primary outcome variable. A patient was considered to experience diagnostic inertia if the healthcare professional failed to interpret correctly an altered TC screening result; that is the professional failed to start a follow-up programme of the patient to confirm or discard a diagnosis of dyslipidaemia.

The following secondary variables were considered: gender; personal history of diseases (hypertension, diabetes, CHD and stroke), personal history of smoking, counselling about diet and exercise (Yes or No), body mass index (BMI) (in $\mathrm{kg} / \mathrm{m}^{2}$ ), age (in years), systolic and diastolic blood pressure (in $\mathrm{mmHg}$ ), fasting blood glucose (FBG) (in mmol/L) and lipid profile (TC and HDL-C, in $\mathrm{mmol} / \mathrm{L}$ ).

The BMI, FBG, blood pressure and lipid profile were obtained using the standard methods. In some patients the BMI was not determined, in which case it was recorded as "not measured". Data concerning the personal history of diseases, the smoking habit, the gender and the age were obtained at the patient interview and corroborated from the charts. Any counselling was recorded in the clinical history.

After obtaining all the data, the variables were grouped as follows (WHO, 1997): 1) BMI: “not measured", low or normal $\left(\mathrm{BMI}<25 \mathrm{~kg} / \mathrm{m}^{2}\right)$, overweight $\left(\mathrm{BMI} \geq 25 \mathrm{~kg} / \mathrm{m}^{2}\right.$ and $\mathrm{BMI}<30$ $\mathrm{kg} / \mathrm{m}^{2}$ ) and obese (BMI $\left.\geq 30 \mathrm{~kg} / \mathrm{m}^{2}\right) ; 2$ ) personal history of cardiovascular disease (CVD): having had CHD or stroke; and 3) TC values: TC $\geq 6.2 \mathrm{mmol} / \mathrm{L}$ and $\mathrm{TC}<6.2 \mathrm{mmol} / \mathrm{L}$ (NCEP and ATP III, 2002; Villar Alvarez et al., 2003). 
For each patient all the parameters in the preventive programme were recorded during

104

121 The overall sample comprised 16,905 patients with no personal history of dyslipidaemia and

122 with TC $\geq 5.17 \mathrm{mmol} / \mathrm{L}$. Of these, 15,778 fulfilled the criteria for REGICOR evaluation and 123 124

one morning (systolic and diastolic blood pressure, FBG, BMI, TC and HDL-C). After

collection, and on the same morning as the collection, the physician met the relevant patient and determined whether a future visit should or should not be arranged to confirm or discard a diagnosis of dyslipidaemia. In addition, at the same time the patient could receive personalized advice about exercise or diet.

After the collection and digitalization of the data and grouping the variables, the REGICOR cardiovascular risk function was ascertained in those patients for whom it was applicable. These patients were then classified in risk groups: high $(\geq 20 \%)$ and low $(<20 \%)$. The REGICOR scale estimates the 10-year probability of CHD in patients free of CVD between the ages of 30 and 74 years (Marrugat et al., 2007). CVD predictive variables: gender, age, lipid profile (TC and HDL-C), systolic and diastolic blood pressure, diabetes and smoking.

The same procedure was followed in those patients for whom the SCORE was applicable (version TC/HDL-C). The risk groups were (Conroy et al., 2003): high ( $\geq 5 \%)$ and low (<5\%).

The SCORE estimates the 10-year risk of cardiovascular death in patients aged 40-65 years with no previous CVD. The variables in this model are: age, gender, TC, HDL-C, systolic blood pressure, and smoking.

Sample size

13,597 for SCORE. Thus, using a significance of 5\% and a maximum expected proportion $(p=q=50 \%)$, the expected error in the estimation of the proportion of diagnostic inertia was 
$1250.75 \%$ in the overall sample, $0.78 \%$ in the REGICOR patients, and $0.84 \%$ in the SCORE 126 patients.

127 Statistical analysis

128 The descriptive analysis was performed using the standard methodology in health sciences

129 (frequencies, percentages, means and standard deviations). Multivariate logistic regression

130 models were used to estimate the adjusted odds ratio (OR) in order to analyse the association

131 between diagnostic inertia and the study variables. For the overall sample the ORs were adjusted

132 for: gender; personal history of diseases and smoking, BMI group, counselling, TC group, and

133 age as a quantitative variable. Another model was performed with the total sample using the

134 current status of the CVRF (systolic blood pressure, TC and FBG), instead of the personal

135 history of hypertension or diabetes mellitus, and TC $\geq 6.20 \mathrm{mmol} / \mathrm{L}$. For the REGICOR sample

136 the ORs were adjusted for: REGICOR risk group, BMI group, and counselling. For the SCORE

137 sample, the ORs were adjusted for SCORE risk group, personal history of diabetes, BMI group,

138 and counselling. The rest of the variables in all the models were not taken into account due to

139 collinearity issues. The prognostic probabilities of inertia were also studied in multivariate

140 models to produce charts in order to aid interpretation of the results. The goodness-of-fit of the

141 models was tested by the likelihood ratio test. Furthermore, the unadjusted ORs were calculated

142 for all the secondary variables. All the analyses were done with a level of significance of $5 \%$ and

143 the associated confidence interval (CI) of each parameter was calculated. All the analyses were

144 done with IBM SPSS Statistics 19.

145 Ethical considerations

146 This study was approved by the Conselleria de Sanitat-Miguel Hernández University

147 institutional review committee (Valencian Community) with reference number AVS-UV1.07X. 
148 This institution did not participate in data collection, analysis or interpretation, or in the decision

149 to approve or disapprove publication of the final manuscript. In addition, the data were

150 anonymized and encrypted, satisfying the data protection law.

151 As our study was population-based and non-interventional, using data from medical

152 records, no informed consent was required. The institutional review committee approved this

153 procedure and ensured that information access was completely restricted. In addition, its use was

154 in line with current legislation.

155

156

RESULTS

157

Total sample

158 Table 1 summarizes the information concerning the overall sample $(n=16,905)$. Most of those 159 who participated in the study were women (60.6\%), there was a high prevalence of CVRF 160 (hypertension, $17.3 \%$; diabetes, $3.5 \%$; smoking, $22.1 \%$ ), almost $4 \%$ of CVD, and the vast 161 majority of the patients had TC concentrations below $6.20 \mathrm{mmol} / \mathrm{L}(69.5 \%)$. Table 1 also shows 162 the unadjusted ORs for all the secondary variables.

163 The magnitude of inertia was $52.0 \%$ (95\% CI: $51.2-52.7 \%)$. Significantly associated 164 factors $(\mathrm{p}<0.05)$ in the multivariate models were: hypertension, smoking, higher BMI 165 (overweight and obesity) or "not measured" BMI, TC $\geq 6.2 \mathrm{mmol} / \mathrm{L}$ and higher values of the 166 control parameters of the CVRF (systolic blood pressure, FBG and TC). These results were 167 similar to the unadjusted ORs (Table 1).

168 REGICOR sample

169 In the REGICOR sample ( $\mathrm{n}=15,778)$, the proportion of inertia was $51.9 \%$ (95\% CI: $51.1-52.7 \%)$.

170 Significantly associated factors were: a high REGICOR $(\geq 20 \%)(\mathrm{OR}=6.49,95 \%$ CI: $3.84-10.98$, 
171

172

173

$\mathrm{p}<0.001$ ), obesity or "not measured" BMI (BMI $<25 \mathrm{~kg} / \mathrm{m}^{2} \rightarrow \mathrm{OR}=1$; BMI $25-29.9 \mathrm{~kg} / \mathrm{m}^{2} \rightarrow$ $\mathrm{OR}=1.11,95 \%$ CI: $1.03-1.20, \mathrm{p}=0.08 ; \mathrm{BMI} \geq 30 \mathrm{~kg} / \mathrm{m}^{2} \rightarrow \mathrm{OR}=1.21,95 \%$ CI: 1.11-1.33, $\mathrm{p}<0.001$; BMI "not measured" $\rightarrow \mathrm{OR}=1.32,95 \% \mathrm{CI}: 1.15-1.52, \mathrm{p}<0.001$ ), and counselling about $\operatorname{diet}(\mathrm{OR}=1.13,95 \% \mathrm{CI}: 1.01-1.25, \mathrm{p}=0.03)$.

Figure 1A shows a Cartesian chart of the risk groups according to the REGICOR on the $\mathrm{X}$ axis and prognostic probability of inertia on the $\mathrm{Y}$ axis. The chart shows that persons with a high risk had a greater probability of inertia.

\section{SCORE sample}

In the analysis done for the SCORE sample $(n=13,597)$ the proportion of inertia was $51.7 \%$ (95\% CI: 50.9-52.5\%). Significantly associated factors were: a high SCORE $(\geq 5 \%)(\mathrm{OR}=2.85$, 95\% CI: 2.34-3.47, $\mathrm{p}<0.001)$, diabetes ( $\mathrm{OR}=1.27,95 \%$ CI: 1.02-1.59; $\mathrm{p}=0.04)$, a higher BMI (overweight and obesity) or "not measured" BMI (BMI $<25 \mathrm{~kg} / \mathrm{m}^{2} \rightarrow$ OR=1; BMI $25-29.9 \mathrm{~kg} / \mathrm{m}^{2}$ $\rightarrow \mathrm{OR}=1.13,95 \%$ CI: $1.04-1.23, \mathrm{p}=0.01 ; \mathrm{BMI} \geq 30 \mathrm{~kg} / \mathrm{m}^{2} \rightarrow \mathrm{OR}=1.19,95 \%$ CI: $1.08-1.31$, $\mathrm{p}<0.001$; BMI "not measured" $\rightarrow \mathrm{OR}=1.31,95 \% \mathrm{CI}: 1.12-1.53, \mathrm{p}<0.001$ ), and counselling about $\operatorname{diet}(\mathrm{OR}=1.15,95 \% \mathrm{CI}: 1.03-1.29, \mathrm{p}=0.01)$.

Figure 1B shows a Cartesian chart of the risk groups according to the SCORE on the $\mathrm{X}$ axis and prognostic probability of inertia on the $\mathrm{Y}$ axis. The chart shows that persons with a greater cardiovascular risk experienced more inertia.

\section{DISCUSSION}

This study shows that a greater cardiovascular risk is related to experiencing diagnostic inertia, when the physician fails in the interpretation of altered TC levels in patients who have no personal history of dyslipidaemia. This greater cardiovascular risk thus leads to an association 
194 between cardiovascular risk factors and diagnostic inertia. These risk factors were hypertension,

195 higher systolic blood pressure, smoking, a high BMI (overweight and obesity) or "not-measured"

196 BMI, higher TC concentrations, a high probability of developing a lethal or nonlethal CVD, a

197 personal history of diabetes and higher values of FBG. In addition, dietary advice was also

198 associated with diagnostic inertia.

199 Most previous studies differ from ours in these associations (Palazón-Bru et al., 2014), as

200 only one paper found an association between the presence of cardiovascular risk factors and lack

201 of a correct diagnosis of dyslipidaemia when there existed alterations in the levels of HDL-C

202 (Palazón-Bru et al., 2014). On the other hand, the study by Sepehri et al. did, though, find an

203 association between having a high REGICOR and experiencing clinical inertia for the treatment

204 of obesity by personalized counselling to lose weight (Sepehri et al., 2014).

205 These results are of concern, as these patients have a very high likelihood of suffering

206 CVD if no preventive measures are taken. Controlling blood pressure, the lipid profile, body

207 weight, diabetes and ceasing to smoke are the main measures. Of note, too, was the greater

208 inertia in persons offered personalized advice about adequate nutrition. This may be because

209 healthcare professionals (physicians and nurses) prefer to give dietary advice rather than measure

210 the TC, because the concentration of TC will decrease if the patient follows this advice.

211 Furthermore, these results were seen during a cardiovascular preventive activities programme, in

212 which the healthcare professionals had to either confirm or discard the diagnosis of

213 dyslipidaemia. We found that half of the patients did not undergo a second measurement of TC,

214 even though many were diagnosed with other CVRF and they should have had their lipid profile

215 controlled to avoid CVD. This may be because most of these patients had multiple disorders and

216 were polymedicated (Pedrera Carbonell et al., 2005), so that the healthcare professional decided 
217 not to order a dyslipidaemia confirmatory test at that time, as this would only increase the

218 therapeutic complexity of the patient. Finally, a factor that we thought might have influenced the

219 decision to monitor the patient was that the healthcare professional would accept borderline TC

220 figures (TC $<6.20 \mathrm{mmol} / \mathrm{L}$ ) as normal (NCEP and ATP III, 2002; Villar Alvarez et al., 2003). Our

221 results, though, unexpectedly showed that greater inertia was committed in persons with non-

222 borderline TC figures. Given that the aim of the study was restricted to determining factors

223 associated with this inertia, a qualitative study should be undertaken to attempt to determine the

224 reasons why the healthcare professionals fail to adhere to the clinical practice guidelines when

225 diagnosing dyslipidaemia. This would enable us to corroborate the theories put forward (dietary

226 advice instead of a second drug; patients with multiple diseases or on multiple drugs for whom

227 the professional does not wish to increase the therapeutic complexity) and thus provide further

228 understanding that would aid the healthcare professional when diagnosing dyslipidaemia, and

229 which would hopefully result in an earlier diagnosis of the disorder.

230 The results of this study suggest the need to design measures aimed at reducing this

231 diagnostic inertia. Worryingly, this diagnostic inertia was associated with a greater

232 cardiovascular risk, both when assessed from a history of CVRF (or using the values of the

233 control parameters) and when using a scoring system. A possible solution to this problem might

234 be the inclusion of training courses in the health centres to remind the healthcare providers of the

235 cut points for the diagnosis of the various CVRF. In addition, as suggested by others (Palazón-

236 Bru et al., 2014; Sepehri et al., 2014), in order to reduce inertia it might be beneficial to integrate

237 some sort of alarm in the computerized electronic records systems in the event that a TC

238 measurement is abnormal. This would help the healthcare professional see that a diagnosis of 
239 dyslipidaemia should be confirmed in a patient who has an altered screening for TC. The end

240 result of this could be a reduction in the incidence of CHD.

241 Limitations and strengths of the study

242 The main strength of this study is that it is the first to examine the association between diagnostic

243 inertia in dyslipidaemia and the cardiovascular risk, as measured with probabilistic functions

244 (REGICOR and SCORE). The results are therefore innovative. In addition, the large sample size

245 and the participation of all the primary care physicians and nurses in the Valencian Community

246 provide external validity to our conclusions.

247 Concerning selection bias, it should be recalled that we are evaluating data from a

248 cardiovascular preventive programme, in which all the healthcare professionals had been

249 instructed to undertake cardiovascular preventive activities with all their patients. This begs the

250 reflection about what the situation would actually be in daily clinical practice; i.e., when the

251 healthcare professionals follow their own criteria for ordering screening tests for the diagnosis of

252 dyslipidaemia. This remains to be examined in future studies, which will then enable comparison

253 with the present results. Another limitation concerns the fact that we were unable to include

254 certain variables that could affect the outcome, such as psychosocial factors of both the

255 healthcare professionals and the patients. This remains for future studies, once the above-

256 mentioned qualitative study has been undertaken and the results analysed.

257 As regards measurement bias, the teams taking the measurements were requested to use

258 reliable devices and to undertake the clinical interview correctly. Nevertheless, only TC was

259 assessed as a lipid parameter to diagnose dyslipidaemia. The reason for not using low-density

260 lipoprotein cholesterol, HDL-C or triglycerides is because in the year the preventive programme

261 was carried out the Spanish clinical guidelines only advised the use of this parameter (Villar 
262 Alvarez et al., 2003). Finally, even though the data are from 2003-2004, we should nevertheless

263 consider that the problem of diagnostic inertia (though it was not yet referred to as such) has

264 been the subject of study since the 1980s. Even nowadays it still exists, despite newer guidelines

265 and changes in the diagnostic cut points (Palazón-Bru et al., 2014). In other words, the results of

266 this study, whilst not very recent, can still indicate the need for diagnostic inertia to be

267 considered at the current time.

268

269

CONCLUSIONS

270 Diagnostic inertia occurred in over half the patients with no personal history of dyslipidaemia but

271 who had an altered screening test and who attended a preventive activities programme.

272 Worryingly, the healthcare professionals committed greater inertia in the patients who had a

273 higher likelihood of CVD.

274 Given the relevance of the problem found, measures are needed to reduce the magnitude

275 of inertia, particularly in the case of patients with a high cardiovascular risk.

\section{ACKNOWLEDGEMENTS}

278 The authors thank Ian Johnstone for help with the English language version of the text. 


\section{REFERENCES}

Conroy RM, Pyörälä K, Fitzgerald AP, Sans S, Menotti A, De Backer G, De Bacquer D,

Ducimetière P, Jousilahti P, Keil U, Njølstad I, Oganov RG, Thomsen T, Tunstall-Pedoe H, Tverdal A, Wedel H, Whincup P, Wilhelmsen L, Graham IM; SCORE project group. 2003.

Estimation of ten-year risk of fatal cardiovascular disease in Europe: the SCORE project.

European Heart Journal 24: 987-1003.

Del Cura González I, Arribas Mir L, Coutado A. 2003. Actividades preventivas en la mujer. Atención Primaria 32: 121-142.

Gil-Guillén V, Orozco-Beltrán D, Pérez RP, Alfonso JL, Redón J, Pertusa-Martínez S, Navarro J, Cea-Calvo L, Quirce-Andrés F, Merino-Sánchez J, Carratalá C, Martín-Moreno JM. 2010. Clinical inertia in diagnosis and treatment of hypertension in primary care: quantification and associated factors. Blood Pressure 19: 3-10.

Instituto Nacional de Estadística. 2004. Available at http://www.ine.es (accessed October 2014).

Marrugat J, Subirana I, Comín E, Cabezas C, Vila J, Elosua R, Nam BH, Ramos R, Sala J, Solanas P, Cordón F, Gené-Badia J, D'Agostino RB; VERIFICA Investigators. 2007. Validity of an adaptation of the Framingham cardiovascular risk function: the VERIFICA Study. Journal of 
Epidemiology and Community Health 61: 40-47. Erratum in: Journal of Epidemiology and

300 Community Health 61: 655.

301

302 National Cholesterol Education Program (NCEP) Expert Panel on Detection, Evaluation, and

303 Treatment of High Blood Cholesterol in Adults (Adult Treatment Panel III). 2002. Third Report

304 of the National Cholesterol Education Program (NCEP) Expert Panel on Detection, Evaluation,

305 and Treatment of High Blood Cholesterol in Adults (Adult Treatment Panel III) final report.

306 Circulation 106: 3143-3421.

307

Palazón-Bru A, Gil-Guillén VF, Orozco-Beltrán D, Pallarés-Carratalá V, Valls-Roca F, Sanchís-

Domenech C, Martín-Moreno JM, Redón J, Navarro-Pérez J, Fernández-Giménez A, Pérez-

Navarro AM, Trillo JL, Usó R, Ruiz E. 2014. Is the Physician’s Behaviour in Dyslipidaemia

311 Diagnosis in Accordance with Guidelines? Cross-Sectional Escarval Study. PLoS ONE 9:

312 e91567.

314 Pareja Bezares A, Alvarez Pasquín MJ, Batalla Martínez C, Comín Bertrán E, Gómez Marco JJ,

315 Niño Martín V, Piñeiro Guerrero R. 1999. Prevención de enfermedades infecciosas. Atención

316 Primaria 24: 99-117. 
318 Pedrera Carbonell V, Gil Guillén V, Orozco Beltrán D, Prieto Erades I, Schwarz Chavarri G,

319 Moya García I. 2005. Características de la demanda sanitaria en las consultas de medicina de

320 familia de un área de salud de la Comunidad Valenciana. Atención Primaria 35: 82-88.

Phillips LS, Branch WT, Cook CB, Doyle JP, El-Kebbi IM, Gallina DL, Miller CD, Ziemer DC,

323 Barnes CS. 2001. Clinical inertia. Annals of Internal Medicine 135: 825-834.

Robledo de Dios T, Ortega Sánchez-Pinilla R, Cabezas Peña C, Forés García D, Nebot Adell M,

Córdoba García R. 2003. Recomendaciones sobre el estilo de vida. Atención Primaria 32: 30-44.

Sepehri A, Gil-Guillén VF, Palazón-Bru A, Orozco-Beltrán D, Carratalá-Munuera C, Castell EC,

Rizo-Baeza M. 2014. Are obese patients assisted in losing weight? The American Journal of Managed Care 20: e122-128. preventivas cardiovasculares. Atención Primaria 32: 15-29. 
337 Wilson PW, D'Agostino RB, Levy D, Belanger AM, Silbershatz H, Kannel WB. 1998.

338 Prediction of coronary heart disease using risk factor categories. Circulation 97: 1837-1847.

339

340 World Health Organization (WHO). 1997. Obesity: Preventing and Managing the Global

341 Epidemic. Report of a WHO Consultation of Obesity. Geneva: WHO.

342

343 World Health Organization (WHO). 2007. Prevention of cardiovascular disease: Guideline for

344 assessment and management of cardiovascular risk. Available at

345 http://whqlibdoc.who.int/publications/2007/9789241547178_eng.pdf(accessed July 2014).

347 World Health Organization (WHO). 2014. The top 10 causes of death. Available at

348 http://www.who.int/mediacentre/factsheets/fs310/en/index.html (accessed July 2014). 
1

Predicted probability of diagnostic inertia for dyslipidaemia for primary cardiovascular prevention patients.

Abbreviations: REGICOR, REgistre GIroní del COr; SCORE, Systematic COronary Risk Evaluation. 

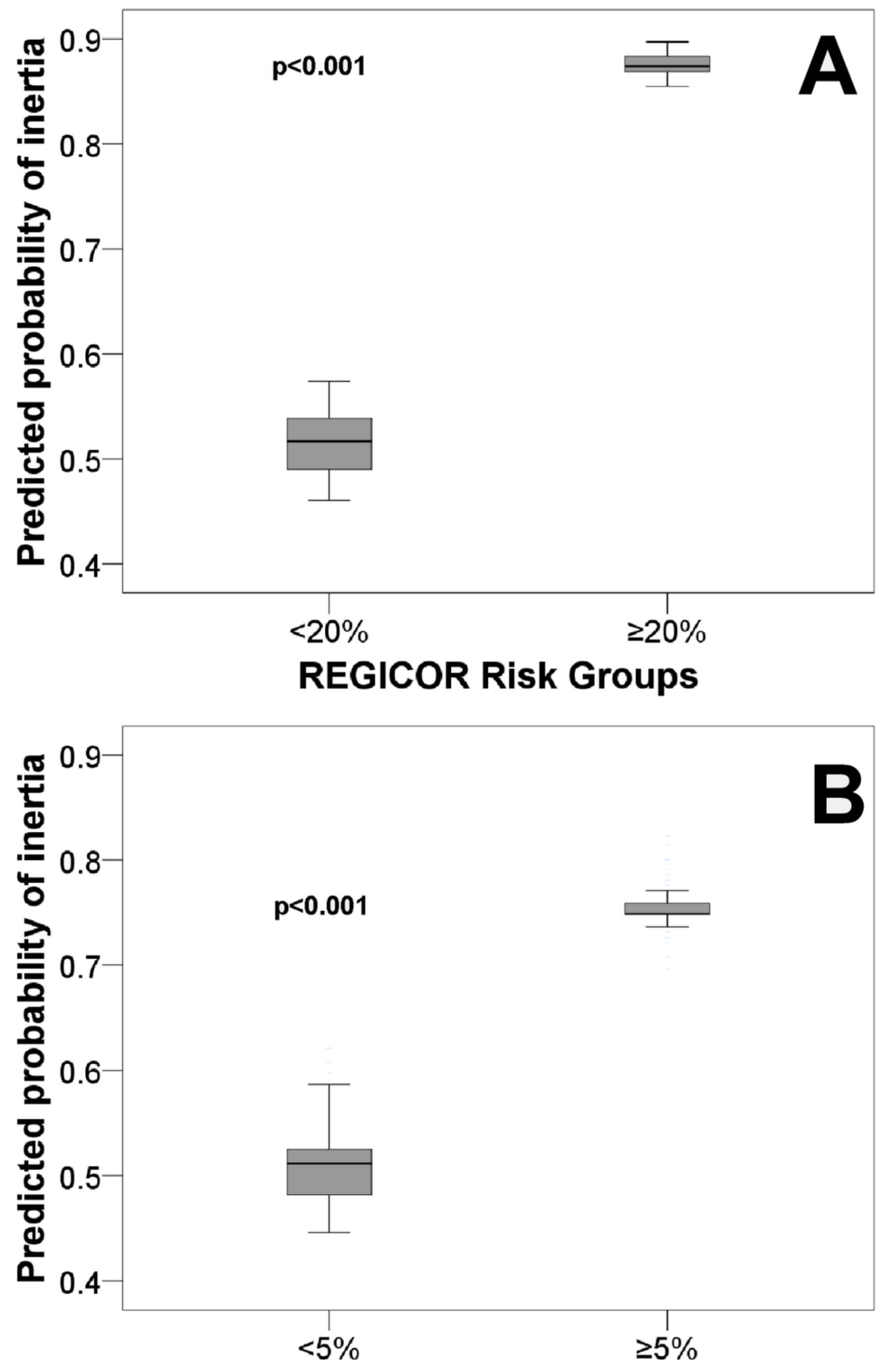


\section{Table $\mathbf{1}_{\text {(on next page) }}$}

Analysis of diagnostic inertia for dyslipidaemia at primary health care centres in the Valencian Community (Spain). 2003-2004 data.

Abbreviations: Adj. OR: adjusted odds ratio; Unadj. OR: unadjusted odds ratio; $\mathrm{Cl}$, confidence interval; REGICOR, REgistre GIroní del COr; SCORE, Systematic COronary Risk Evaluation; HDL, high density lipoprotein; CVD, cardiovascular disease; BMI, body mass index; N/M, not in the models. ORs were adjusted for gender; personal history of hypertension, diabetes, smoking and CVD; BMI groups, counselling (diet and exercise), total cholesterol values (as a categorical variable) and age. Systolic and diastolic blood pressure, total and HDL cholesterol were not included in the multivariate model due to collinearity with the personal history of hypertension and $\mathrm{TC} \geq 6.2 \mathrm{mmol} / \mathrm{L}$. A second model was performed (current status of the cardiovascular risk factors) replacing TC $\geq 6.20 \mathrm{mmol} / \mathrm{L}$, personal history of hypertension and diabetes by TC (in mmol/L), systolic blood pressure and fasting blood pressure. In this last model, diastolic blood pressure and HDL cholesterol were not included due to collinearity with systolic blood pressure and TC. Goodness-of-fit of the models: 1) Personal history of cardiovascular risk factors: $\left.X^{2}=4,750.1 P<0.001 ; 2\right)$ Current status of the cardiovascular risk factors: $X^{2}=4,834.1 P<0.001{ }^{a}$ : Reference. ${ }^{b}$ : Only when the scoring system was applicable. ${ }^{c}$ : Adjusted with the current status of the cardiovascular risk factors (systolic blood pressure, total cholesterol and fasting blood glucose). d: Prevalence of inertia. 


\begin{tabular}{|c|c|c|c|c|c|c|}
\hline Variable & $\begin{array}{c}\text { Total } \\
16,905 \\
\mathrm{n}(\%) / \mathrm{x} \pm \mathrm{s}\end{array}$ & $\begin{array}{c}\text { Inertia } \\
8,783 \\
(52.0 \%) \\
\mathrm{n}(\%) / \mathrm{x} \pm \mathrm{S}^{\mathrm{d}}\end{array}$ & $\begin{array}{l}\text { Unadj. OR } \\
(95 \% \mathrm{CI})\end{array}$ & $P$ & $\begin{array}{l}\text { Adj. OR } \\
(95 \% \mathrm{CI})\end{array}$ & $P$ \\
\hline Age (Years) & $54.7 \pm 9.9$ & $54.8 \pm 9.9$ & $1.00(1.00,1,01)$ & 0.12 & $1.00(0.99,1.00)$ & 0.13 \\
\hline REGICOR (probability of event) & $5.8 \pm 3.6$ & $6.5 \pm 4.0$ & $1.12(1.11,1.14)$ & $<0.001$ & $\mathrm{~N} / \mathrm{M}$ & $\mathrm{N} / \mathrm{M}$ \\
\hline $\begin{array}{l}\text { REGICOR risk groups: } \\
\geq 20 \% \\
<20 \% \text { a,b }\end{array}$ & $\begin{array}{c}128(0.8) \\
15,650(99.2)\end{array}$ & $\begin{array}{c}112(87.5) \\
8,074(51.6)\end{array}$ & $6.57(3.89,11.10)$ & $<0.001$ & $\mathrm{~N} / \mathrm{M}$ & $\mathrm{N} / \mathrm{M}$ \\
\hline SCORE (probability of event) ${ }^{\mathrm{b}}$ & $1.3 \pm 1.9$ & $1.6 \pm 2.3$ & $1.22(1.19,1.25)$ & $<0.001$ & $\mathrm{~N} / \mathrm{M}$ & $\mathrm{N} / \mathrm{M}$ \\
\hline $\begin{array}{l}\text { SCORE risk groups: } \\
\geq 5 \% \\
<5 \% \text { a,b }\end{array}$ & $\begin{array}{c}551(4.1) \\
13,046(95.9)\end{array}$ & $\begin{array}{c}414(75.1) \\
6,616(50.7)\end{array}$ & $2.94(2.41,3.57)$ & $<0.001$ & $\mathrm{~N} / \mathrm{M}$ & $\mathrm{N} / \mathrm{M}$ \\
\hline $\begin{array}{l}\text { Gender: } \\
\text { Male } \\
\text { Female }^{\mathrm{a}}\end{array}$ & $\begin{array}{c}6,664(39.4) \\
10,241(60.6)\end{array}$ & $\begin{array}{l}3,679(55.2) \\
5,104(49.8)\end{array}$ & $1.24(1.17,1.32)$ & $<0.001$ & $0.97(0.91,1.05)$ & 0.49 \\
\hline $\begin{array}{l}\text { Personal history of hypertension: } \\
\text { Yes } \\
\mathrm{No}^{\mathrm{a}}\end{array}$ & $\begin{array}{l}2,923(17.3) \\
13,982(82.7)\end{array}$ & $\begin{array}{l}2,087(71.4) \\
6,696(47.9)\end{array}$ & $2.72(2.49,2.96)$ & $<0.001$ & $4.27(3.85,4.73)$ & $<0.001$ \\
\hline $\begin{array}{l}\text { Personal history of diabetes: } \\
\text { Yes } \\
\mathrm{No}^{\mathrm{a}}\end{array}$ & $\begin{array}{c}592(3.5) \\
16,313(96.5)\end{array}$ & $\begin{array}{c}351(59.3) \\
8,432(51.7)\end{array}$ & $1.36(1.15,1.61)$ & $<0.001$ & $1.16(0.96,1.41)$ & 0.13 \\
\hline $\begin{array}{l}\text { Personal history of smoking: } \\
\text { Yes } \\
\mathrm{No}^{\mathrm{a}}\end{array}$ & $\begin{array}{c}3,739(22.1) \\
13,166(77.9)\end{array}$ & $\begin{array}{l}2,779(74.3) \\
6,004(45.6)\end{array}$ & $3.45(3.18,3.74)$ & $<0.001$ & $4.94(4.50,5.42)$ & $<0.001$ \\
\hline $\begin{array}{l}\text { Personal history of CVD: } \\
\text { Yes } \\
\mathrm{No}^{\mathrm{a}}\end{array}$ & $\begin{array}{c}639(3.8) \\
16,266(96.2)\end{array}$ & $\begin{array}{c}341(53.4) \\
8,442(51.9)\end{array}$ & $1.06(0.91,1.24)$ & 0.47 & $0.86(0.71,1.03)$ & 0.10 \\
\hline $\begin{array}{l}\text { BMI groups }\left(\mathrm{kg} / \mathrm{m}^{2}\right): \\
<25^{\mathrm{a}} \\
25-30 \\
\geq 30 \\
\text { Not measured }\end{array}$ & $\begin{array}{c}4,157(24.6) \\
7,355(43.5) \\
4,357(25.8) \\
1,036(6.1)\end{array}$ & $\begin{array}{c}2,038(49.0) \\
3,803(51.7) \\
2,360(54.2) \\
582(56.2)\end{array}$ & $\begin{array}{l}1.11(1.03,1.20) \\
1.23(1.13,1.34) \\
1.33(1.16,1.53)\end{array}$ & $\begin{array}{c}0.01 \\
<0.001 \\
<0.001\end{array}$ & $\begin{array}{l}1.08(0.99,1.18) \\
1.10(1.00,1.22) \\
1.26(1.07,1.48)\end{array}$ & $\begin{array}{l}0.09 \\
0.06 \\
0.01\end{array}$ \\
\hline $\begin{array}{l}\text { Diet counselling: } \\
\text { Yes } \\
\mathrm{No}^{\mathrm{a}}\end{array}$ & $\begin{array}{c}14,407(85.2) \\
2,498(14.8)\end{array}$ & $\begin{array}{l}7,542(52.3) \\
1,241(49.7)\end{array}$ & $1.11(1.02,1.21)$ & 0.02 & $1.02(0.91,1.15)$ & 0.72 \\
\hline Exercise counselling: & & & & & & \\
\hline
\end{tabular}




\begin{tabular}{|c|c|c|c|c|c|c|}
\hline $\begin{array}{l}\text { Yes } \\
\mathrm{No}^{\mathrm{a}}\end{array}$ & $\begin{array}{c}14,369(85.0) \\
2,536(15.0)\end{array}$ & $\begin{array}{l}7,476(52.0) \\
1,307(51.5)\end{array}$ & $1.02(0.93,1.11)$ & 0.71 & $0.99(0.88,1.12)$ & 0.86 \\
\hline $\begin{array}{l}\text { Total cholesterol values }(\mathrm{mmol} / \mathrm{L}): \\
\geq 6.2 \\
<6.2^{\mathrm{a}}\end{array}$ & $\begin{array}{l}5,158(30.5) \\
11,747(69.5)\end{array}$ & $\begin{array}{l}4,189(81.2) \\
4,594(39.1)\end{array}$ & $6.73(6.22,7.29)$ & $<0.001$ & $8.33(7.63,9.09)$ & $<0.001$ \\
\hline Systolic blood pressure $(\mathrm{mmHg})^{\mathrm{c}}$ & $128.9 \pm 17.3$ & $130.5 \pm 17.9$ & $1.01(1.01,1.01)$ & $<0.001$ & $1.01(1.01,1.01)$ & $<0.001$ \\
\hline Diastolic blood pressure $(\mathrm{mmHg})$ & $78.4 \pm 10.4$ & $79.2 \pm 10.7$ & $1.02(1.01,1.02)$ & $<0.001$ & $\mathrm{~N} / \mathrm{M}$ & $\mathrm{N} / \mathrm{M}$ \\
\hline Total cholesterol $(\mathrm{mmol} / \mathrm{L})^{\mathrm{c}}$ & $6.0 \pm 0.7$ & $6.2 \pm 0.8$ & $5.90(5.50,6.32)$ & $<0.001$ & $6.58(6.10,7.09)$ & $<0.001$ \\
\hline HDL cholesterol (mmol/L) & $1.5 \pm 1.2$ & $1.7 \pm 1.1$ & $0.98(0.94,1.02)$ & 0.41 & $\mathrm{~N} / \mathrm{M}$ & $\mathrm{N} / \mathrm{M}$ \\
\hline Fasting blood glucose $(\mathrm{mmol} / \mathrm{L})^{\mathrm{c}}$ & $5.5 \pm 1.4$ & $5.5 \pm 1.4$ & $1.09(1.06,1.11)$ & $<0.001$ & $1.05(1.02 .1 .08)$ & $<0.001$ \\
\hline
\end{tabular}

1 